\title{
Empirical study on the influences of environmental music on human factors in manual labor companies based on computerized digital audio analysis
}

\author{
Qingli Liu' ${ }^{*}$ \\ ${ }^{1}$ Art School, JangSu University, Zhenjiang, JiangSu, 212013, China
}

\begin{abstract}
Environmental music, or ambient music, refers to music played in certain conditions in order to achieve a specific function or effect. In China, environmental music is rarely used in factory plants. The environment for physical work is filled with noises and less tranquil than the mental work environment. Most employees in a factory plant are physical laborers. The present study first selects environmental music with certain characteristics and apply computerized waveform analysis to the pieces to identify their similarities and differences. Next, music is played, in two different experiments, in the assembly plant of a certain fabrication factory. Its impact on the emotion and productivity of employees is measured and discussed. Further, this work will explore the practical impact of environmental music on human factors in the factory plant through the analysis of experimental data. Experiment results demonstrate that music tempo has the most prominent effect on productivity in the factory plant being studied. Music with a moderato tempo can significantly reduce fatigue experienced during work, create a pleasant work ambiance and enhance the average productivity by $2.92 \%$.
\end{abstract}

\section{Psychological analysis of workers in a physical work environment}

Emotions of a person are characterized by constant changes. In addition, the scientific interest in studying the influence of music listening on different psychological functions has substantially increased[1]. Some research shows that music yields a huge impact on several factors related to a person[2]. In contrast, a few studies also show that music might not affect listeners on a big scale[3]. Whatever the case may be, researchers should be aware that their object of study is the impact of music on mood, not on emotions. Mood and emotion are two distinct aspects of a human being[4].

The auditory experience of people working in physical labor environments is permeated with the sound of equipment knocking against each other. These noises are often negative stimuli to employees. They can affect employees' mood and even lead to negative effects such as fluctuations in blood pressure and tachycardia. In addition, employees working in a physical labor environment generally perform simple and repetitive tasks, which can elicit boredom and lethargy when they last for a long time. This can hugely impact productivity, be a hindrance to the smooth operation of production and even cause labor accidents, resulting in the waste of time and production materials. Therefore, environmental music should be used in the factory plants to relieve boredom, improve willingness to work, decrease the negative effects posed by noises and increase productivity.

\section{Effects of environmental music on physical laborers}

According to sources, "In 1886, a general manager and engineer of an automobile company in Chicago, Frank Morton, undertook a trial of music playing in his factory" [5]. "During the World War II, wartime factories played music in their factory plants to increase production of arms"[6]. We shall discuss the effects of music on employees' mood based on relevant researches in pursuit of a theory framework that is more comprehensive. Fiske pointed out vividly that music is the language that expresses moods. Contemporary theories show that music can bridge the communication between different communities. Resting on his numerous theories on music and its effects, Fiske concluded that the influences of music on emotions varied according to past experiences of the listener[7]. He clarified the difference between an aesthetical response and an emotional one. On the one hand, listener will juxtapose its experiences and believes onto the movements of timbre, rhythm and beats of music, leading to correspondent changes in emotion. On the other hand, an aesthetical response refers to the listener's understanding of the internal relationship between patterns of timbre, rhythm beat.

Playing selected music pieces in a factory plant can,

"Corresponding author's e-mail: 52745656@qq.com 
firstly, mitigate noises. Countering noises with harmonic sound can prevent negative mental effect on employees. Secondly, listening to music help employees shift their attention, alleviate feeling of irritation and maintain a good state for work. Employees generally tend to feel mental and physical weariness as well as loneliness during work. Ambient music can help channel stress out, ease the discomfort occasioned by exhaustion and increase cooperativeness. For example, in a famous tobacco factory in Louisville, employees work under mechanical noises of $95 \mathrm{~dB}$ - a huge number and an awful work environment. Effects were evident after ambient music is employed. Employees generally acknowledged that it wasn't unnecessary for ambient music to be louder than the mechanical noises for the former to purify the latter. The main reason for this is that human ears opt automatically for relatively more harmonious sound among all kinds of noises, thereby discarding the unpleasant ones. Another reason consists in the fact that noises emitted by machines only cover a small range of frequencies, whereas ambient music has a larger sound field and wide frequency range. The extent to which ambient music is received is thus greater than that in the case of noises. Hence, employees are able to choose, in a biological way, environmental music to defend themselves against noises.

\section{Experiments on the application of environmental music in physical labor work environment}

\subsection{Background}

In the assembly plant of a certain factory, music is played, in two different experiments, in order to study its impact on the emotion and work performance of workers. The first experiment (Experiment III) focuses chiefly on the influence of environmental music on productivity. The second mainly studies the impact of a single piece of music on short-term positive emotion changes and productivity.

\subsection{General overview of the work condition in the assembly plant of a certain factory}

The assembly plant of a certain factory produces contact pieces, one of the four basic components of an automotive connector, a type of device that electric engineering technicians often come to contact with. The assembly plant principally handles the processing of the contact pieces, which has a short duration of on average 3 to 4 seconds. Employee performance is evaluated based on the number of pieces processed in a day. Measurement of the music experiments can thus be quantified via daily production value of employees.

\subsection{Experiment equipment and environment}

The assembly plant has a surface of $200 \mathrm{~m} 2$. The main production equipment is $10 \mathrm{KN}$ bench press (figure 1). Operations are rhythmic and patterned. The plant is noisy (around $85 \mathrm{~dB}$ ). Four speakers, one audio amplifier with a capacity of $200 \mathrm{~W}$ and one MP3 player are installed in the plant (figure 2, figure 3). Due to limiting conditions in the plant, all speakers are placed in the same line on a side wall. Environment music is played by the supervisor of the plant in accordance with experiment requirements.

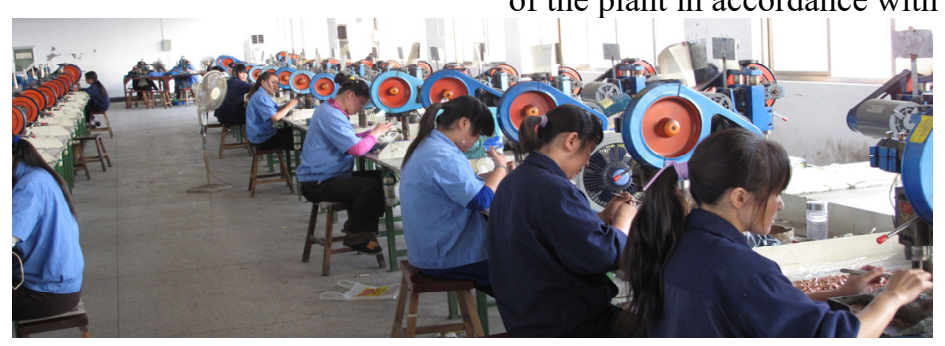

Figure 1. The assembly plant of a certain factory

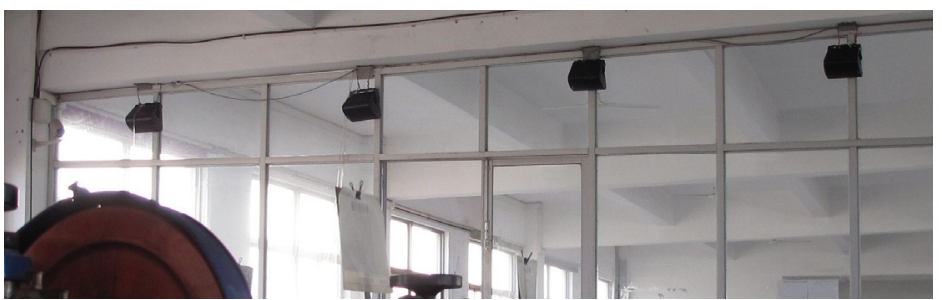

Figure 2. Placement of speakers in the assembly plant 


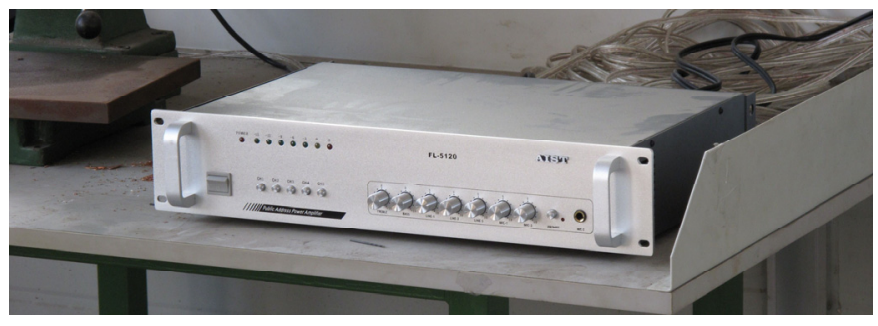

Figure 3. Placement of audio amplifier in the plant

\subsection{Experiment participants}

Participants of this experiment are all assembly workers in the assembly plant of the factory. There are seven participants and $90 \%$ of them are female. Their ages range from 30 to 40 with an average of 35 . The workers are either middle school or high school graduates. Their work experience range from/ vary between 12 to 36 months with an average of 1.78 year. None of them had any former musical education. Time devoted to listening music each day differ among the participants, ranging from none to 2 hours with an average of 0.32 hour. Employees are paid by the piece.

\subsection{Experiment design}

3.5.1First experiment. Method: since the employees are paid by the piece, their production is recorded on a "daily production card". The card is filled daily by the person in charge after weighting the production of each person. The unit of measurement for the experiment is pieces per day. Daily production cards of half a month are first collected as reference. Next, daily production cards over the period of one month (September) are collected to identify possible change in production and evaluate the effects of music on efficiency.

Music playing schedule: the first group of music is played during the first half of the month, the second group during the second half. Music is played during the first 30 minutes of each hour starting from eight o'clock and pauses during lunch break (12:00 - 13:00).

3.5.2Second experiment Method: basing on data obtained from the first experiment, a group of music which had a bigger influence on productivity is selected and employed in another experiments which lasts one week. The production is obtained by "music-production" card. Each day, one piece of music from the selected group is played on a loop. Effects of the properties of music, such as rhythm, tempo and dynamics, on productivity are analyzed to select the best music. Music is played during the first 30 music of each hour.

\subsection{Environmental music selection and computerized audio analysis}

Two groups of music are selected as environmental music based on parameters such as tempo, dynamics and speed. The first group includes (1) "Souvenirs d'Enfance" by Richard Clayderman, (2) "Liebestraum" by Clayderman, (3) excerpt from "Rhapsody on a Theme of Paganini", (4) "Childhood Memory" by Bandari and (5) "Humoresque" by Dvoř́k. The second group comprises of (1) "Anthem" by Ronan Hardiman, (2) "Chariots of Fire" by Vangelis, (3) "The Only Flower in the World" by 12 Girls Band, (4) "Vanessa's First Smiles" by Clayderman and (5) excerpt from a modern electric symphony "Manju".

To find similarities and differences between these two groups of music, we used digital audio technology, feeding the selected pieces into professional audioprocessing software for waveform analysis (figure 4, figure 5). The first group of five environmental music pieces are fed into the software as tracks in an order identical to the order in which they were introduced above. In order to highlight the general patterns of the sound frequency of the five pieces, the waveform photos are represented in a minimized manner in figure 4 . It is observable from the images that tracks (1), (2) and (3) produced relatively smooth waves, whereas track (4) has a more intense frequency and a larger amplitude. Compared to other pieces, track (5) has the smoothest frequency and the least amplitude.

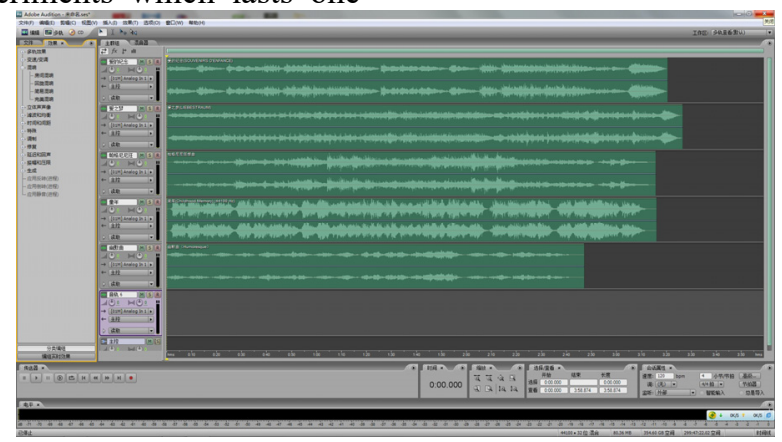

Figure 4. Sound wave frequency analysis on the first group of environmental music 


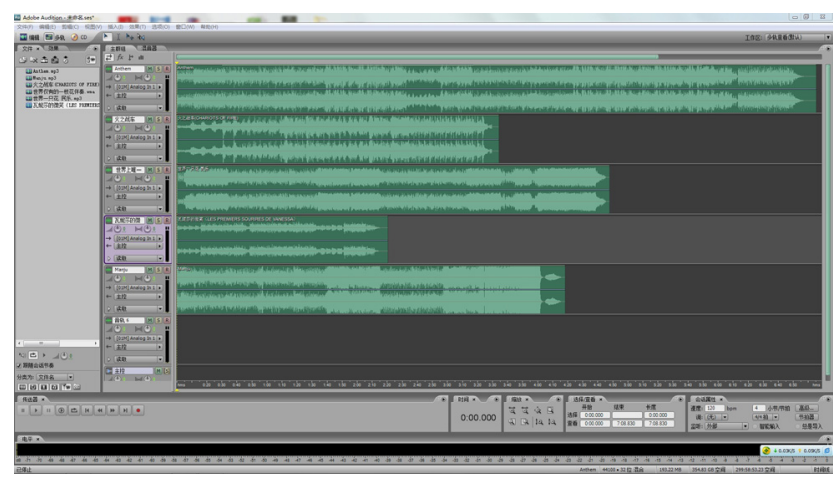

Figure 5. Sound wave frequency analysis on the second group of environmental music

Differences between waveforms of the first and the second group can be easily discerned after the second group was fed into the software in the order of their introduction in this paper. Among the second group, "Vanessa's First Smiles" has the least fluctuation and amplitude, while "Manju" has the largest frequency and amplitude.

In general, musical pieces in the first group have a signature of either $3 / 4$ or $4 / 4$ and an andante tempo (around $60 \mathrm{bpm}$ ). They do not have intense rhythms and their dynamic is medium soft. Tracks in the second group all have a signature of $4 / 4$. They are more rhythmic. Instruments such as electronic drums or drum kits are used in each of the pieces. They generally have a moderato tempo (about $88 \mathrm{bpm}$ ) and a mezzo forte dynamic.

\section{Results and analysis}

As table 1 shows, the average daily production of the plant during a two-week period is 9405 pieces. In experiment III, the same average increased to 9625, while the result is 9684 when the second group is employed as background music. See Picture- 6 for production distribution details.

Table 1. Impact of environmental music on worker productivity in a certain fabrication plant

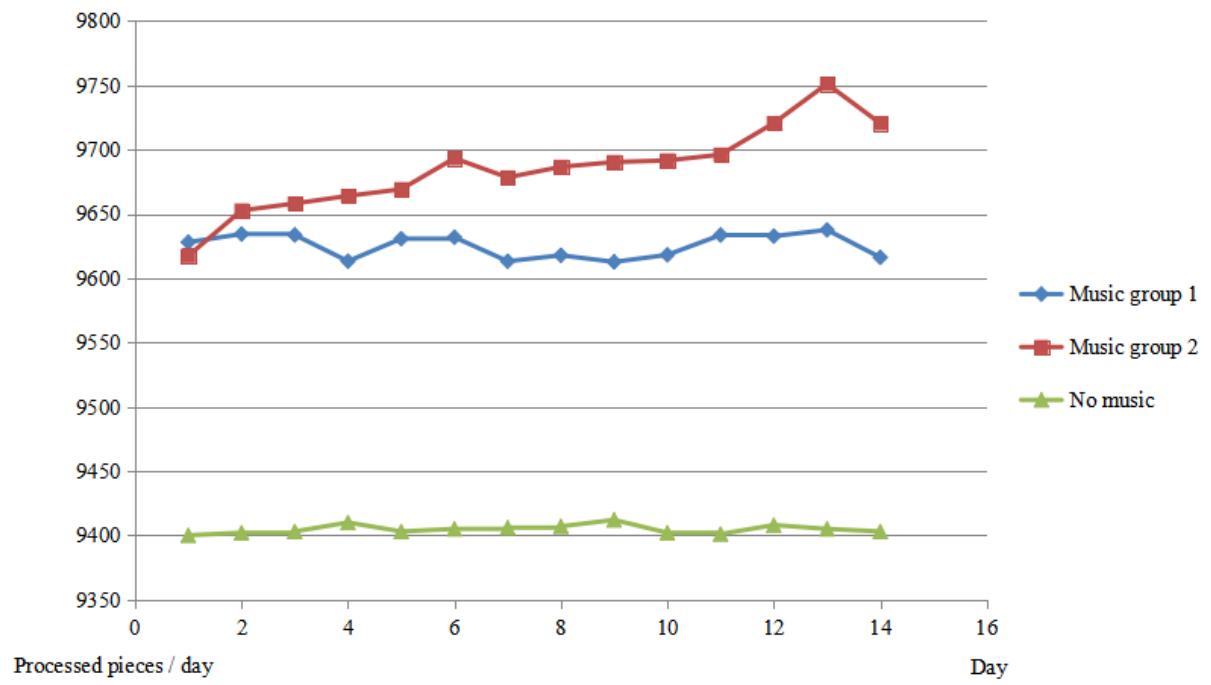

As table 1 demonstrates, significant difference exist between production quantities depending on whether background music is played or not. Additionally, the production when the second group is played is manifestly higher than when the first is played. Calculation shows that production increased by $2.3 \%$ after changing from no music to the first group of music, whereas the increase is $0.62 \%$ when comparing the results of group one and group two. That is, using the second group of music yields a $2.92 \%$ increase in production compared to when no music is played. Therefore, using music different tempo and dynamics can influence production by their different effects on the enthusiasm and willingness to operate of employees.
The average production per person per minute is calculated from the daily average to be 20 pieces, which corresponds to the average speed of the second group of music. On average, a stamping part is produced every 4 to 5 beats. Of course, the results of our experiment is not as significant as other experiments conducted either in China or abroad. Differences in experiment results are commonly explained by differences in in experiment duration and conditions.

Among the second group of music, "Anthem", "Chariots of Fire" and "Manju" are all made by computer. "Vanessa's First Smiles" has a piano melody and uses drum kit accompaniment. "The Only Flower in the World" has a melody composed by flute, erhu and guzheng and electric music elements as accompaniment. 
All pieces have a 4/4 tempo. In terms of timbre, "Vanessa's First Smiles" is similar to "Souvenirs d'Enfance", "Liebestraum" and "Rhapsody on a Theme of Paganini" of the first group. "The Only Flower in the World" is a piece of "new ethnic music" based on ethnic music and combines elements from contemporary electric music. Though made by computer, "Chariots of Fire" is somewhat unreal and plain in terms of timbre due to the at the time still underdeveloped computer music technology. By contrast, "Anthem" and "Manju" were relatively newer, released at a time where digital music technology is mature, which is why their general quality is better.

Although experiment period is short, the author discovered that all employees had reacted positively to the playing of ambient music through an interview conducted with employees after the first experiment. Employees generally consider both the first group and second had a positive effect on alleviating noises and thus improved their work environment. The first group of music is considered not compatible with their production work for being not rhythmic and melodically overelegant. When the second group of environmental music was played, employee's eagerness to work was stimulated by the majestic, ceremonious and exalted melodies, which reduced monotony as well as inefficient time caused by fatigue, improving productivity. Most employees reported that it was possible to associate music tempo in the second group with their production speed, thereby forming a harmonious rhythm. Based on this, we conducted another 5-day small experiment (Experiment II) after all experiments finished to analyze the detailed influences that the second group of ambient music has on employees.

After collecting experiment results as shown in table 2 , it is visible that "Manju" and "Anthem" have the most significant effect on productivity enhancement. During the two days where these two tracks are played, the average production per person is, respectively, 9758 pieces and 9746 pieces. These two tracks are both in major scale and have a simple but majestic rhythm. Beats of electric drums are evident in both of them. They resemble each other in terms of rhythm, tempo and speed. Orchestration with contemporary electric instruments render them intense and powerful. When it comes to their differences, the Irish style of "Anthem" together with its simulated human voice makes it relatively gentler, while "Manju", combining simulated human voice with a lowto-medium tempo main melody played by string instruments, can be described as "exhilarating".

Table 2. Data of the second experiment

\begin{tabular}{cccccc}
\hline & Monday & Tuesday & Wednesday & Thursday & Friday \\
\hline Music name & Anthem & Chariots of Fire & $\begin{array}{c}\text { The Only Flower } \\
\text { in the World }\end{array}$ & $\begin{array}{c}\text { Vanessa's } \\
\text { First Smiles }\end{array}$ & Manju
\end{tabular}

\section{Average production} (piece/person)
9723

In a second interview conducted at the end of the second experiment, we learnt that employees were the most impressed by "Manju". Interviewees reported that sensations of refreshment and motivation were felt when it was being played. Its tempo is in synchrony with the rhythm of production. Some employees resorted to adjust their production rate with the beats, making the rhythm of music in a harmonic unity with that of production. It is thus clear that its speed, its electric drum beats and its majestic and exhilarating rhythm has led the employees to experience the process of their production work as a kind of "enjoyment". In addition, "Anthem", with a style similar to "Manju", also left a big impression on employees. Some of them expressed that they experienced the beauty of music in its simulated human voices, which stimulated their eagerness to work. Among the other three pieces, "The Only Flower in the World" and "Chariots of Fire" did not leave any strong impression. As for "Vanessa's First Smiles", due to its gentleness and gracefulness, it achieved a limited effect in inspiring eagerness to work compared to all other songs.

\section{Conclusion}

Through analysis of data form the two experiments, it can be established that playing ambient music in a physical work environment can enhance work envrionment, lower the effect of noises and positively impact human factors. Rhythmic, elevating music in major scales are more conducive to the improvement of work efficiency in a factory plant. Music with indiscernible tempo, gentle rhythm and dolce tunes is not suitable for usage in factory plants. Employees working in such entrainment can also experience the harmonious resonation between music and labor. In addition, music with electric music technologies is welcomed and loved by the employees.

\section{References}

1. Anja, B., Stefan, E., Denis, K. Christian, B., Lutz,J.(2018) The effect of background music on inhibitory functions: An ERP study.J.Frontiers In Human Neuroscience., 293:1-6

2. Gagnon, L., Peretz, I. (2003) Mode and tempo relative contributions to "happy-sad" judgements in equitone melodies.J. Cognition \& Emotion., 17:2540.

3. Juslin, P. N., Liljeström, S., Västfjäll, D., Barradas, G., Silva, A.(2008) An experience sampling study of emotional reactions to music: Listener, music, and situation.J. Emotion.,5: 668-683. 
4. Meyer, L. B. (1957) Emotion and meaning in music.J.Music \& Letters., 3:278-279

5. Fu, B., Si, Y. (1991). Environmental Music Aesthetics. Renmin University of China Publishing, The Beijing.

6. Zhang, J. (2010). Questions and studies on contemporary researches on environmental music in China. Chinese Music.J.003: 69-75.
7. Kivy, P. (1991). Music alone: Philosophical reflections on the purely musical experience. Cornell University Publishing, The Ithaca.

8. Langer, S. (1967) Mind: An Essay on Human Feeling.Vol.1. Science.J.157:1543-1544 